\title{
Synthesis of Conjugated Polymer Consisting of Three-Component Aromatic Units via Two-Step Cross- Dehydrogenative-Coupling Reactions
}

Chie Tanaka ${ }^{\text {a }}$, Junpei Kuwabara ${ }^{\text {a }}$, Takeshi Yasuda ${ }^{\text {b }}$, and Takaki Kanbara ${ }^{\text {a* }}$

${ }^{a}$ Tsukuba Research Center for Energy Materials Science (TREMS), Graduate School of Pure and Applied Sciences, University of Tsukuba, 1-1-1 Tennodai, Tsukuba, Ibaraki 305-8573, Japan

${ }^{\mathrm{b}}$ Research Center for Functional Materials, National Institute for Materials Science (NIMS), 1-2-1 Sengen, Tsukuba, Ibaraki 305-0047, Japan

*Corresponding author. Tel.: +81-29-853-5066, fax: +81-29-853-4490,

E-mail address: kanbara@ims.tsukuba.ac.jp

\begin{abstract}
A Pd-catalyzed two-step cross-dehydrogenative-coupling sequence enabled the synthesis of a $\pi$-conjugated polymer consisting of three-component aromatic units, without the use of prefunctionalized starting substrates. When using 1,2,4,5-tetrafluorobenzene as the starting substrate, the cross-coupling reactions proceeded efficiently and the undesired homocoupling reaction was suppressed, producing a new donor-acceptor $\pi$-conjugated polymer. The introduction of a $4 H$-cyclopenta[2,1-b:3,4- $b^{\prime}$ ]-dithiophenediyl unit between the tetrafluorophenylene units enhanced coplanarity along the polymer chain, thus lowering the energy gap of the polymer. The obtained polymer was also evaluated for use as an emitting material in organic light-emitting diodes.
\end{abstract}

Keywords: Conjugated polymers; Polycondensation; Cross-dehydrogenative-coupling reaction; Three component units; Emitting materials 


\section{Introduction}

Catalytic direct arylation of aromatic compounds via $\mathrm{C}-\mathrm{H}$ bond cleavage has attracted increasing attention as a simple method that helps eliminate the need for prior preparation of organometallic reagents [1-6]. Several groups have attempted to utilize this strategy in polycondensation for the synthesis of $\pi$-conjugated polymers, which are considered promising materials for optoelectronic devices such as organic photovoltaic cells, field-effect transistors, and light-emitting diodes (Scheme 1a) [7-13]. Recently, strategies for direct $\mathrm{sp}^{2} \mathrm{C}-\mathrm{H}$ functionalization toward the synthesis of $\pi$-conjugated polymers have been expanded to cross-dehydrogenative-coupling polycondensation (Scheme 1b) [14-17]. The protocol is based on the direct C-H/C-H cross-coupling reaction between two kinds of aromatic monomers, which provides straightforward access to alternating $\pi$-conjugated polymers, without the need for the prior preparation of dibrominated aromatic monomers or organometallic monomers. This protocol also allows us to eliminate the end-capping treatment of the terminal reactive functional groups of the polymer, which is known to degrade the semiconducting performance [18-21]. However, the synthetic examples are currently very specific. Previous studies indicated that the use of polyfluorobenzenes as a targeting aromatic monomer was crucial to control the selectivity in the successive $\mathrm{C}-\mathrm{H}$ metalation steps and suppress undesired homocoupling reactions [14,17]. To expand the applicability of the synthetic protocol, we herein focused on the synthesis of $\pi$-conjugated polymers via a two-step cross-dehydrogenative-coupling sequence (Scheme 2). This protocol furnished a $\pi$-conjugated polymer consisting of three-component aromatic units, without the use of prefunctionalized starting substrates. The introduction of an aromatic unit between the tetrafluorophenylene units was expected to improve the coplanarity along the polymer chain. The optical properties of the polymer and its performance in an organic light-emitting diode (OLED) were also evaluated.

$\langle$ Scheme 1>

$\langle$ Scheme 2>

\section{Experimental}

\subsection{Materials}

1,2,4,5-Tetrafluorobenzene, 4,4-bis(2-ethylhexyl)-4H-cyclopenta[2,1-b:3,4-b']dithiophene, 3,3'-dihexyl2,2'-bithiophene, and other chemicals were received from commercial suppliers and used without further purification. Anhydrous DMF and DMSO were purchased from Kanto chemical and used as a dry solvent.

\subsection{General measurements and characterization}

NMR spectra were recorded on Bruker AVANCE-600 and AVANCE-400 NMR spectrometers. Gel permeation chromatography (GPC) measurements were carried out using a SHIMADZU prominence GPC system equipped with polystyrene gel columns, using $\mathrm{CHCl}_{3}$ as an eluent after calibration with polystyrene standards at $40{ }^{\circ} \mathrm{C}$. Ultraviolet visible absorption spectra and photoluminescence (PL) spectra were recorded on a JASCO V-630 and a Hitachi F-2700 spectrophotometers, respectively. The quantum yields of the emission $(\varphi)$ from polymers in films were measured using a JASCO FP-6500 spectrofluorometer with an integrating sphere. The HOMO energy 
level was estimated by photoelectron yield spectroscopy (PYS) using a Riken Keiki AC-3 spectrometer. Elemental analyses were carried out with a PerkinElmer 2400 CHN Elemental Analyzer. All the manipulations for the reactions were carried out under a nitrogen atmosphere using a glove box or standard Schlenk technique.

\subsection{Monomer synthesis}

A mixture of $\mathrm{Pd}(\mathrm{OAc})_{2}(10.1 \mathrm{mg}, 0.045 \mathrm{mmol}), \mathrm{Ag}_{2} \mathrm{CO}_{3}(1.49 \mathrm{~g}, 5.4 \mathrm{mmol})$, acetic acid (206 $\left.\mu \mathrm{L}, 3.6 \mathrm{mmol}\right)$, 1,2,4,5-tetrafluorobenzene (1.89 mL, $18 \mathrm{mmol}$ ), and 4,4-bis(2-ethylhexyl)-4H-cyclopenta[2,1-b:3,4- $\left.b^{\prime}\right]$ dithiophene $(725 \mathrm{mg}, 1.8 \mathrm{mmol})$ was stirred in a mixture of anhydrous DMSO $(6.0 \mathrm{~mL})$ for $1 \mathrm{~h}$ at $120{ }^{\circ} \mathrm{C}$ under nitrogen atmosphere. After cooling to room temperature, the mixture was extracted by $\mathrm{CHCl}_{3}$. $\mathrm{The} \mathrm{CHCl}_{3}$ solution was washed with $1 \mathrm{M} \mathrm{HCl}$ and dried with sodium sulfate. After filtration, the resulting crude product was purified by chromatography on silica gel with $\mathrm{CHCl}_{3}$ to afford 2,6-bis(2,3,5,6-tetrafluorophenyl)-4,4-bis(2-ethylhexyl)-4Hcyclopenta[2,1-b:3,4- $b^{\prime}$ ]dithiophene, M1, as an orange oil (579.8 mg, $46 \%$ yield). ${ }^{1} \mathrm{H}$ NMR (400 MHz, $\left.298 \mathrm{~K}, \mathrm{CDCl}_{3}\right)$ $\delta: 7.52(\mathrm{t}, J=3.8 \mathrm{~Hz}, 2 \mathrm{H}), 7.03-6.94(\mathrm{~m}, 2 \mathrm{H}), 2.04-1.90(\mathrm{~m}, 4 \mathrm{H}), 1.07-0.86(\mathrm{~m}, 18 \mathrm{H}), 0.71(\mathrm{td}, J=6.8,1.1 \mathrm{~Hz}, 6 \mathrm{H})$, $0.62(\mathrm{td}, J=7.4,1.5 \mathrm{~Hz}, 6 \mathrm{H}) .{ }^{19} \mathrm{~F}$ NMR $\left(376 \mathrm{MHz}, 298 \mathrm{~K}, \mathrm{CDCl}_{3}\right): \delta-140.2--140.4(\mathrm{~m}),-141.4-141.6(\mathrm{~m}) .{ }^{13} \mathrm{C}\left\{{ }^{1} \mathrm{H}\right\}$ $\operatorname{NMR}\left(150 \mathrm{MHz}, 298 \mathrm{~K}, \mathrm{CDCl}_{3}\right) \delta 158.6,146.7\left(\mathrm{dm}, J_{\mathrm{C}-\mathrm{F}}=208 \mathrm{~Hz}\right), 143.5\left(\mathrm{dm}, J_{\mathrm{C}-\mathrm{F}}=250 \mathrm{~Hz}\right), 140.1,128.3,125.6$, 116.0, $103.5\left(\mathrm{t}, J_{\mathrm{C}-\mathrm{F}}=23.1 \mathrm{~Hz}\right), 54.5,43.3,35.5,34.5,28.8,27.6,22.9,14.0,10.8$. Anal. Calcd. for $\mathrm{C}_{37} \mathrm{H}_{38} \mathrm{~F}_{8} \mathrm{~S}_{2}: \mathrm{C}$, 63.59; H, 5.48. Found: C, 63.53; H, 5.66.

\subsection{Polymer synthesis}

A mixture of $\mathrm{Pd}(\mathrm{OAc})_{2}(2.25 \mathrm{mg}, 0.010 \mathrm{mmol}), \mathrm{Ag}_{2} \mathrm{CO}_{3}(165 \mathrm{mg}, 0.60 \mathrm{mmol})$, PivOH $(45.1 \mu \mathrm{L}, 0.40$ $\mathrm{mmol}), \mathrm{K}_{2} \mathrm{CO}_{3}(82.9 \mathrm{mg}, 0.60 \mathrm{mmol}), \mathbf{M 1}(140 \mathrm{mg}, 0.20 \mathrm{mmol})$, and 3,3'-dihexyl-2,2'-bithiophene (66.9 mg, 0.20 $\mathrm{mmol})$ was stirred in a mixture of anhydrous DMF $(1.6 \mathrm{~mL})$ and DMSO $(0.08 \mathrm{~mL})$ for $48 \mathrm{~h}$ at $100{ }^{\circ} \mathrm{C}$ under nitrogen atmosphere. After cooling to room temperature, the mixture was poured into water and extracted by $\mathrm{CHCl}_{3}$. After filtration, the $\mathrm{CHCl}_{3}$ solution was thoroughly washed with $5 \%$ aqueous solution of $\mathrm{HNO}_{3}$ to dissolve residual $\mathrm{Ag}$, an aqueous solution of ethylenediaminetetraacetic acid disodium salt $(\mathrm{pH}=8)$ to remove residual $\mathrm{Pd}$, and distilled water. After filtration through a plug of Celite, the solution was concentrated and reprecipitated into methanol. The precipitates were thoroughly washed with methanol and hexane, and dried under reduced pressure. P1 was isolated as a reddish solid (135 mg, 66\% yield). $\quad M_{\mathrm{n}}=17,300, M_{\mathrm{w}} / M_{\mathrm{n}}=1.82 .{ }^{1} \mathrm{H}$ NMR $\left(600 \mathrm{MHz}, 373 \mathrm{~K}, \mathrm{C}_{2} \mathrm{D}_{2} \mathrm{Cl}_{4}\right)$ : $\delta: 7.62$ (m, 4H), $2.72(\mathrm{t}, J=7.5 \mathrm{~Hz}, 4 \mathrm{H}), 2.07(\mathrm{~m}, 4 \mathrm{H}), 1.73-1.68(\mathrm{~m}, 4 \mathrm{H}), 1.35(\mathrm{~m}, 12 \mathrm{H}), 1.13-0.93(\mathrm{~m}, 18 \mathrm{H}), 0.94(\mathrm{t}, J=$ $7.0 \mathrm{~Hz}, 6 \mathrm{H}), 0.81(\mathrm{t}, J=6.8 \mathrm{~Hz}, 6 \mathrm{H}), 0.73(\mathrm{t}, J=7.5 \mathrm{~Hz}, 6 \mathrm{H}) .{ }^{19} \mathrm{~F} \mathrm{NMR}\left(376 \mathrm{MHz}, 298 \mathrm{~K}, \mathrm{CDCl}_{3}\right): \delta-141.8 .{ }^{13} \mathrm{C}\left\{{ }^{1} \mathrm{H}\right\}$ NMR (150 MHz, $\left.373 \mathrm{~K}, \mathrm{C}_{2} \mathrm{D}_{2} \mathrm{Cl}_{4}\right)$ : $8159.0,145.2$ (m, overlap), 143.2, 140.1, 132.0, 131.3, 128.5, 128.2 125.5, 113.3, 112.0 (m), 54.6, 43.6, 35.8, 34.6, 31.5, 30.4, 29.0, 28.9, 28.8, 27.6, 22.7, 22.4, 13.8, 13.7, 10.6. Anal. Calcd. for $\mathrm{C}_{57} \mathrm{H}_{64} \mathrm{~F}_{8} \mathrm{~S}_{4}: \mathrm{C}, 66.51 ; \mathrm{H}, 6.27$. Found: C, 66.86; H, 6.17.

\subsection{Fabrication and characterization of OLED}

OLED was fabricated in the following configuration: ITO/PEDOT:PSS/light-emitting P1 layer/electron transporting (hole blocking) TPBi layer/LiF/Al. The patterned indium tin oxide (ITO) glass (conductivity: 10 $\Omega /$ square) was precleaned in an ultrasonic bath of acetone and ethanol and then treated in an ultraviolet-ozone 
chamber. A thin layer (40 nm) of PEDOT:PSS was spin-coated onto the ITO at $3000 \mathrm{rpm}$ and air-dried at $110^{\circ} \mathrm{C}$ for $10 \mathrm{~min}$ on a hot plate. The substrate was then transferred to a $\mathrm{N}_{2}$-filled glovebox where it was redried at $110{ }^{\circ} \mathrm{C}$ for $10 \mathrm{~min}$ on a hot plate. A toluene solution of $\mathbf{P 1}(10 \mathrm{mg} / 1 \mathrm{~mL})$ was subsequently spincoated onto the PEDOT:PSS surface to form the light-emitting layer $(47 \mathrm{~nm})$, followed with an annealing process for $10 \mathrm{~min}$ at $80{ }^{\circ} \mathrm{C}$. TPBi $(40$ $\mathrm{nm}), \operatorname{LiF}(1 \mathrm{~nm})$, and $\mathrm{Al}(100 \mathrm{~nm})$ were then deposited onto the active layer with conventional thermal evaporation at a chamber pressure lower than $5 \times 10^{-4} \mathrm{~Pa}$, which provided the devices with an active area of $2 \times 2 \mathrm{~mm}^{2}$. Current-voltage characteristics and luminance of the OLED were simultaneously measured using an ADCMT 6246 DC voltage current source/monitor (ADC CORPORATION) and an LS-100 luminance meter (KONICA MINOLTA JAPAN, INC.), respectively. The electroluminescence (EL) spectra and the coordinates of the CIE chromaticity were measured using an array spectrometer (MCPD-9800-311C, Otsuka Electronics Co, Ltd.).

\section{Results and Discussion}

\subsection{Synthesis and characterization}

Monomer M1 was prepared by the Pd-catalyzed cross-dehydrogenative-coupling of 1,2,4,5tetrafluorobenzene with 4,4-bis(2-ethylhexyl)- $4 H$-cyclopenta[2,1-b:3,4- $\left.b^{\prime}\right]$ dithiophene by referring to literature procedures (Scheme S1) [22]. M1 was fully characterized by NMR and elemental analyses (Fig. S1). The polycondensation reaction of M1 with 3,3'-dihexyl-2,2'-bithiophene was conducted under the optimal conditions described in a previous report [14]. The polycondensation reaction afforded the corresponding polymer P1 with a molecular weight $\left(M_{\mathrm{n}}\right)$ of 17,300 in $66 \%$ yield (Scheme 3$)$.

\section{$\langle$ Scheme 3>}

The chemical structure of $\mathbf{P 1}$ was characterized by NMR spectroscopy and elemental analysis. Assignment of the NMR signals was performed by comparison with the signals of the monomers and a reference polymer (P0, Scheme 4), which was synthesized by cross-dehydrogenative-coupling of 2,2',3,3',5,5',6,6'-octafluorobiphenyl with 3,3'-dihexyl-2,2'-bithiophene [14]. As shown in Fig. 1a, the main signals were assigned to the repeating unit. The integral ratios of the signals essentially agreed with the assignments and were consistent with the alternating structure of P1. The minor signals at $\delta 7.03$ and $7.37 \mathrm{ppm}$ were assignable to a terminal 3,3'-dihexyl-2,2'-bithiophene unit, whereas the minor signals at $\delta 7.14$ and $7.57 \mathrm{ppm}$ were assigned to structural defects in the polymer chain, which were caused by the homocoupling reaction of the 3,3'-dihexyl-2,2'-bithiophene moiety (Fig. S2). However, the integral ratios between the minor defects and the recurring unit in the ${ }^{1} \mathrm{H}$ NMR spectrum indicated that P1 included less than $3 \%$ of the homocoupling defects. The ${ }^{19} \mathrm{~F}$ NMR spectrum supported the alternating structure of P1 (Fig. 1b). The minor signals at $\delta-140.3$ and $-141.5 \mathrm{ppm}$ were assigned to a terminal tetrafluorophenyl unit in the ${ }^{19} \mathrm{~F}$ NMR spectrum, but no signal corresponding to the homocoupling defect of the polyfluoroarene unit in the polymer chain was observed. These results are consistent with the trend mentioned in previous reports $[14,17,23]$.

\section{$<$ Scheme 4>}




\section{$<$ Figure 1>}

\subsection{Optical properties and OLED behavior}

The UV-vis absorption spectra of $\mathbf{P 1}$ and $\mathbf{P 0}$ in the film state are shown in Fig. 2. The absorption of P1 was redshifted as compared with that of $\mathbf{P 0}$ in $\mathrm{CHCl}_{3}$ solution (Fig. S4) and in the film state. The optical bandgaps (E ${ }_{\mathrm{g}}{ }^{\text {opt }}$ ) of P1 and P0 were determined to be 2.37 and $2.96 \mathrm{eV}$, respectively, and the corresponding HOMO levels were 5.60 and $6.07 \mathrm{eV}$, as determined by PYS. While P0 showed a large distortion of the aromatic rings in the octafluorobiphenylene unit, the introduction of a cyclopenta[2,1-b:3,4- $\left.b^{\prime}\right]$ dithiophenediyl unit between the tetrafluorophenylene units could effectively reduce the torsion angle, as was also confirmed by density functional theory (DFT) calculations (Fig. S5). This enhanced coplanarity along the polymer chain lowered the energy gap of the polymer. Intramolecular donor-acceptor interactions between the tetrafluorophenylene and cyclopenta[2,1- $b: 3,4-$ $b^{\prime}$ ]dithiophenediyl units would also be associated with the lowering of the $\mathrm{Eg}_{\mathrm{g}}{ }^{\text {opt }}$ value of P1 [24,25].

\section{<Figure 2>}

A previous report describes the fabrication of an OLED using P0 with light green emission [14]. Since the $\mathbf{P 1}$ film showed orange emission with a higher emission quantum yield $(\varphi=16 \%)$ compared to that of $\mathbf{P 0}(\varphi=9 \%)$, the emission properties of P1 were also evaluated in an OLED. The EL spectrum was consistent with the PL spectrum of P1 (Fig. 3), and the coordinates of the CIE chromaticity diagram were $\mathrm{x}=0.59, \mathrm{y}=0.41$, at $7.0 \mathrm{~mA} \mathrm{~cm}^{-2}($ Fig. S6). The luminance reached $690 \mathrm{~cd} \mathrm{~m}^{-2}$ at a current of $485 \mathrm{~mA} \mathrm{~cm}^{-2}$; the maximum external quantum efficiency (EQE) was $0.32 \%$ in the OLED using P1 (Fig. S7), which was higher than that (0.12\%) in the same OLED using P0 [14]. While the OLED performance with P1 is mediocre, these results indicate that $\mathbf{P 1}$ can serve as the emitting material in these devices.

\section{$<$ Figure 3>}

\section{Conclusion}

The synthesis of a $\pi$-conjugated polymer via a two-step cross-dehydrogenative-coupling sequence is demonstrated. The protocol furnishes a $\pi$-conjugated polymer consisting of three-component aromatic units, without the need for any reactive functional group in the aromatic substrates. The introduction of a third aromatic unit helps tune the energy levels and emission color of the polymer from light green to orange. Therefore, the synthetic protocol can provide easy access to multicomponent semiconducting materials in organic optoelectronic devices with improved step economy. Further studies on extending the usability of the developed synthetic protocol are underway.

\section{Acknowledgement}

The authors thank the Chemical Analysis Division and the OPEN FACILITY, Research Facility Center for Science and Technology, University of Tsukuba, for the measurements of NMR and elemental analysis. This work was supported by Grant-in-Aid for Scientific Research (B) (17H03063) and Challenging Research (18K19103) from 
JSPS.

\section{Appendix A. Supplementary data}

Supplementary data associated with this article can be found, in the online version, at http://dx.doi.org/10.1019/j.synthmet.2019.

\section{References}

[1] L.C. Campeau, K. Fagnou, Chem. Commun. 12 (2006) 1253.

[2] D. Alberico, M.E. Scott, M. Lautens, Chem. Rev. 107 (2007) 174.

[3] R. Rossi, F. Bellina, M. Lessi, C. Manzini, Adv. Synth. Catal. 356 (2014) 17.

[4] T. Satoh, M. Miura, Chem. Lett. 36 (2007) 200.

[5] L. Ackermann, R. Vicente, A.R. Kapdi, Angew. Chem., Int. Ed. 48 (2009) 9792.

[6] Y. Segawa, T. Maekawa, K. Itami, Angew. Chem. Int. Ed. 54 (2015) 66.

[7] S.L. Suraru, J.A. Lee, C.K. Luscombe, ACS Macro Lett. 5 (2016) 724.

[8] J.R. Pouliot, F. Grenier, J.T. Blaskovits, S. Beaupré, M. Leclerc, Chem. Rev. 116 (2016) 14225.

[9] M. Wakioka, F. Ozawa, Asian J. Org. Chem. 7 (2018) 1206.

[10] N.S. Gobalasingham, B.C. Thompson, Prog. Polym. Sci. 83 (2018) 135.

[11] J. Kuwabara, T. Kanbara, Bull. Chem. Soc. Jpn. 92 (2019) 152.

[12] A. Marrocchi, A. Facchetti, D. Lanari, C. Petrucci, L. Vaccaro, Energy Environ. Sci. 9 (2016) 763.

[13] S. Yu, F. Liu, J. Yu, S. Zhang, C. Cabanetos, Y. Gao, W. Huang, J. Mater. Chem. C 5 (2017) 29.

[14] H. Aoki, H. Saito, Y. Shimoyama, J. Kuwabara, T. Yasuda, T. Kanbara, ACS Macro Lett. 7 (2018) 90.

[15] Q. Zhang, M. Chang, Y. Lu, Y. Sun, C. Li, X. Yang, M. Zhang, Y. Chen, Macromolecules 51 (2018) 379.

[16] Q. Zhang, Y.F. Li, L.D. Deng, L.L. Zhao, C.X. Li, Y. Lu, Chinese J. Polym. Sci. 36 (2018) 1019.

[17] L.J. Kang, L. Xing, C.K. Luscombe, Polym. Chem. 10 (2019) 486.

[18] K.H. Hendriks, W. Li, G.H.L. Heintges, G.W.P. van Pruissen, M.M. Wienk, R.A.J. Janssen, J. Am. Chem. Soc. 136 (2014) 11128.

[19] J. Kuwabara, T. Yasuda, S.J. Choi, W. Lu, K. Yamazaki, S. Kagaya, L. Han, T. Kanbara, Adv. Funct. Mater. 24 (2014) 3226.

[20] T. Yasuda, J. Kuwabara, L. Han, T. Kanbara, Mol. Cryst. Liq. Cryst. 620 (2015) 107.

[21] T. Kubodera, M. Yabusaki, V.A.S.A. Rachmat, Y. Cho, T. Yamanari, Y. Yoshida, N. Kobayashi, K. Marumoto, ACS Appl. Mater. Interfaces 10 (2018) 26434.

[22] C. He, S. Fan, X. Zhang, J. Am. Chem. Soc. 132 (2010) 12850.

[23] H. Saito, J. Kuwabara, T. Yasuda, T. Kanbara, Macromol. Rapid Commun. 39 (2018) 1800414.

[24] C. Liu, K. Wang, X. Gong, A. J. Heeger, Chem. Soc. Rev. 45 (2016) 4825.

[25] J. W. Jung, J. W. Jo, E. H. Jung, W. H. Jo, Org. Electron. 31 (2016) 149. 
(a) Direct arylation polycondensation

$\left.\mathrm{n} \mathbf{H} A r^{1}-\mathbf{H}+\mathbf{n} \mathbf{X}-\mathbf{x} \stackrel{\text { Pd cat. }}{\longrightarrow} A r^{1}-A r^{2}\right)_{n}$

(b) Cross-dehydrogenative-coupling polycondensation

$\mathbf{n} \mathbf{H} A r^{1}-\mathbf{H}+\mathbf{n} \mathbf{H} A r^{2}-\mathbf{H} \stackrel{\mathrm{Pd} \text { cat. }}{\longrightarrow}-\mathrm{Ar}^{2}{ }_{\mathrm{n}}$

Scheme 1 . Synthesis of $\pi$-conjugated polymers via $\mathrm{sp}^{2} \mathrm{C}-\mathrm{H}$ bond functionalization.

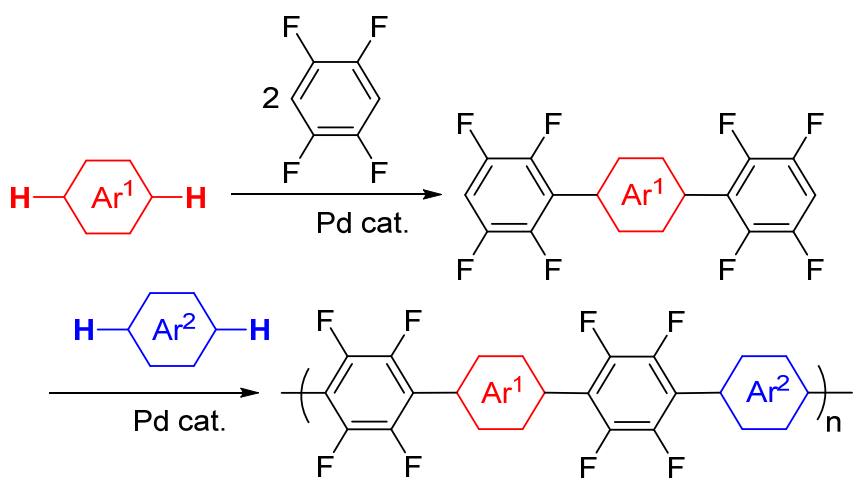

Scheme 2. Two-step cross-dehydrogenative coupling reaction for synthesis of $\pi$-conjugated polymer.

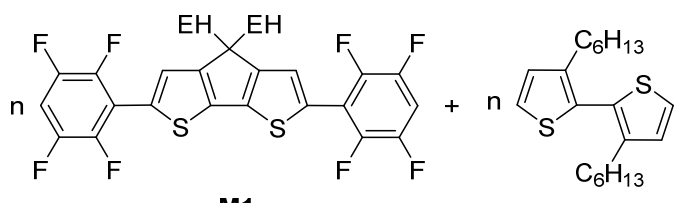

M1

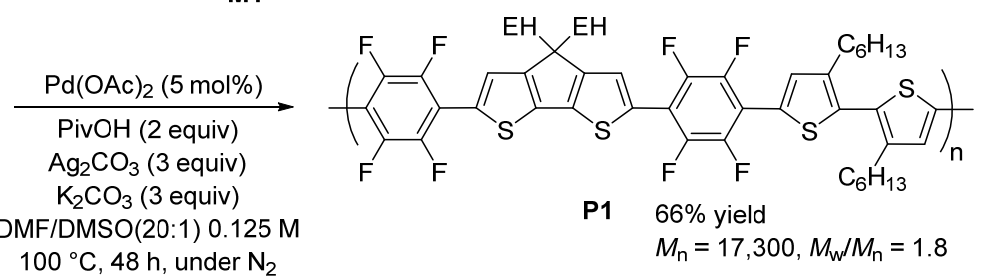

Scheme 3. Synthesis of P1 via cross-dehydrogenative coupling polycondensation.

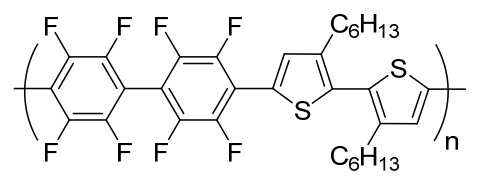

Po

Scheme 4. The chemical structure of $\mathbf{P 0}$. 


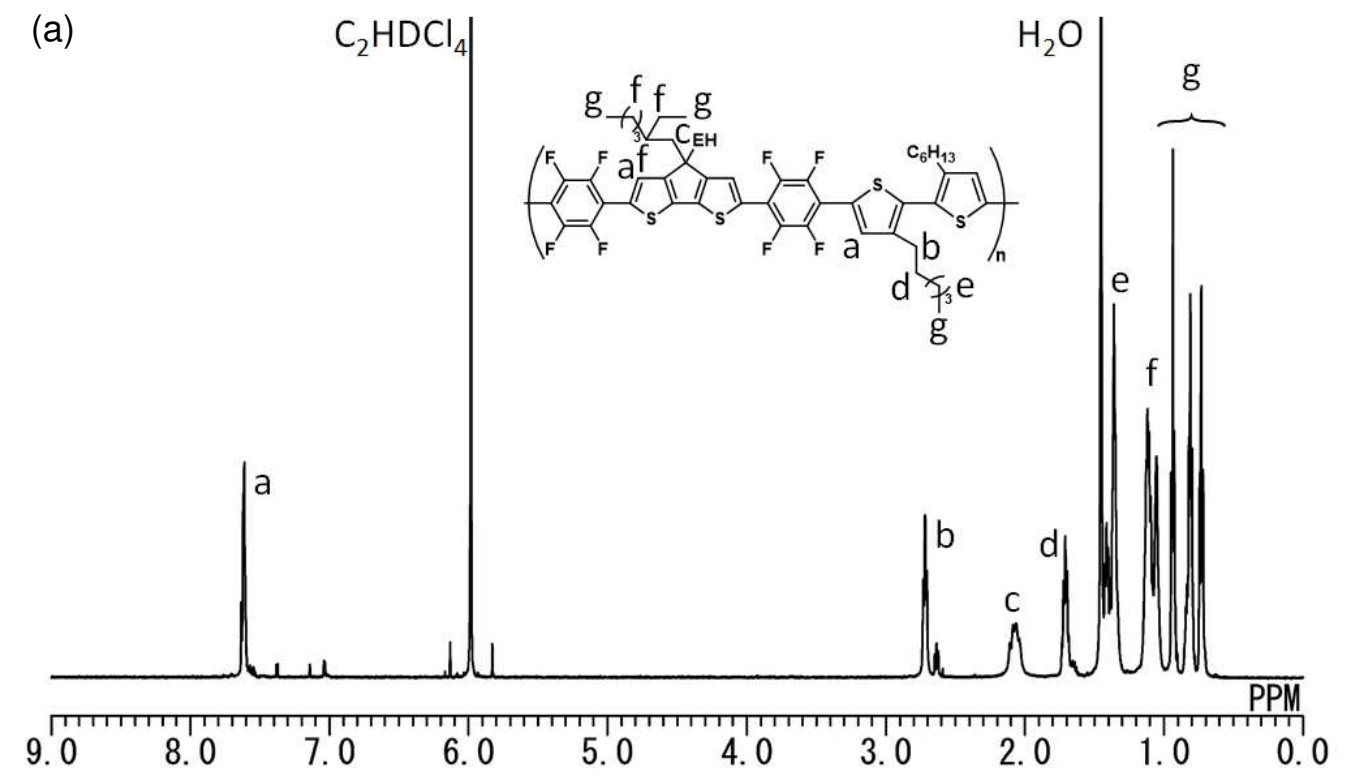

(b)
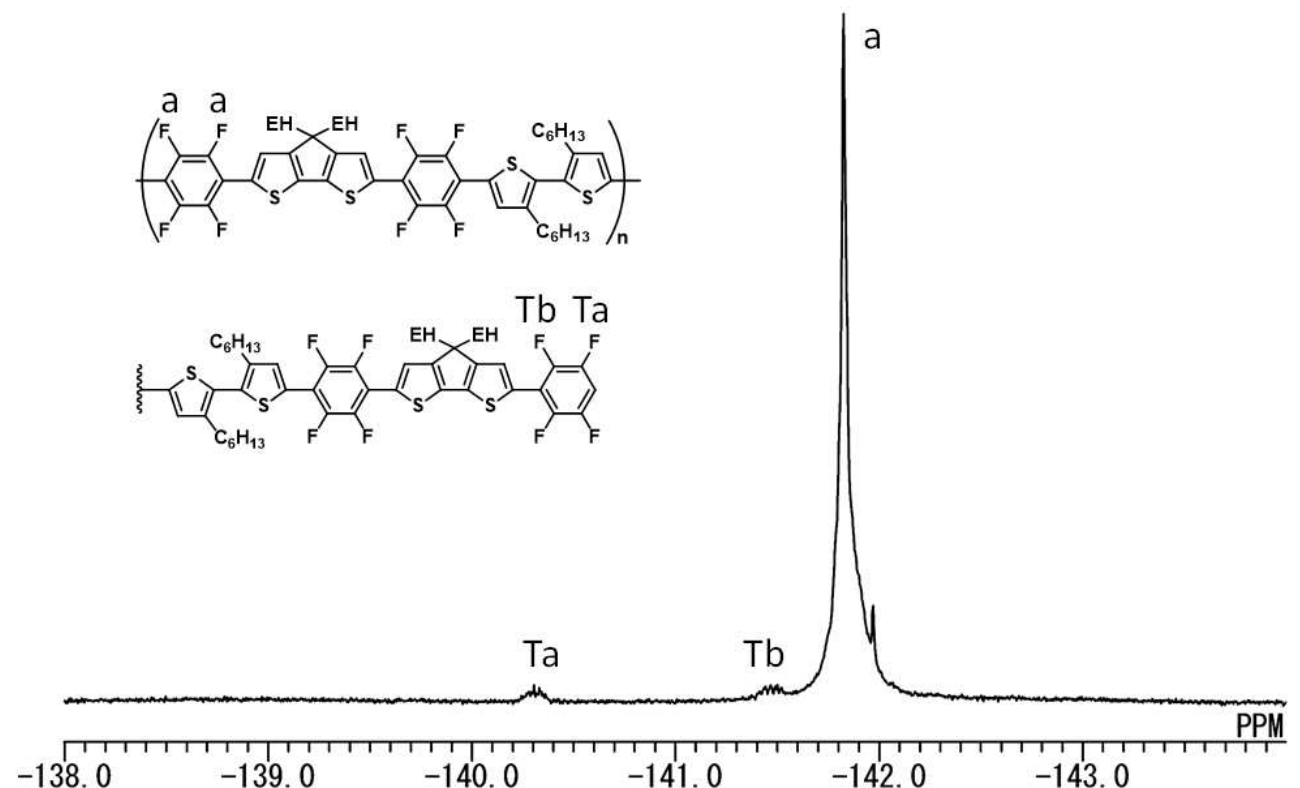

Fig. 1. (a) ${ }^{1} \mathrm{H}\left(600 \mathrm{MHz}, \mathrm{C}_{2} \mathrm{D}_{2} \mathrm{Cl}_{4}, 373 \mathrm{~K}\right.$ ) and (b) ${ }^{19} \mathrm{~F}$ (376 MHz, $\mathrm{CDCl}_{3}, 298 \mathrm{~K}$ ) NMR spectra of $\mathbf{P 1}$. 


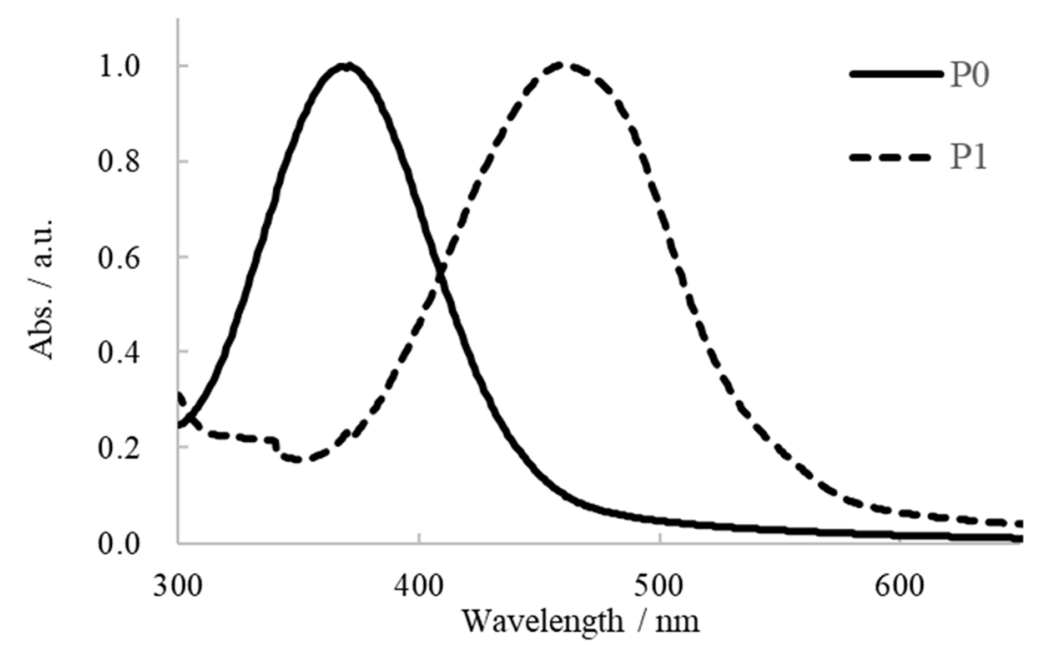

Fig. 2. UV-vis absorption spectra of $\mathbf{P 1}$ and $\mathbf{P 0}$ in the film states.

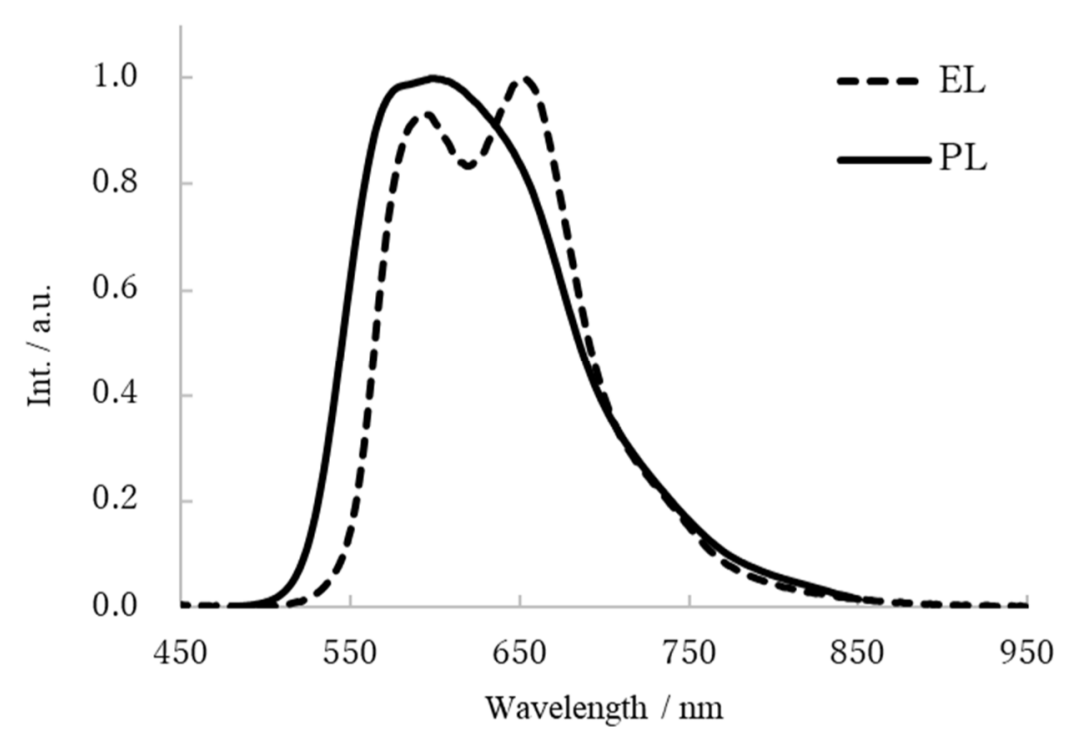

Fig. 3. PL spectrum of thin film of P1 and EL spectrum of OLED using P1 at 6.0 V. 